\title{
As miíases no imaginário de uma população rural no município de Formosa (Goiás), Brasil
}

\author{
Edison Rogerio Cansi ${ }^{1 *}$ \\ Hélio Spindola de Ataíde ${ }^{1}$ \\ Caroline Demo ${ }^{1}$ \\ Rodrigo Gurgel-Gonçalves ${ }^{2}$ \\ José Roberto Pujol-Luz ${ }^{1}$ \\ ${ }^{1}$ Núcleo de Entomologia Forense, Departamento de Zoologia, Instituto de Ciências Biológicas \\ ${ }^{2}$ Laboratório de Parasitologia Médica e Biologia de Vetores, Faculdade de Medicina \\ Universidade de Brasília, Campus Darcy Ribeiro, CEP 70910-900, Brasília - DF, Brasil \\ * Autor para correspondência \\ tiercansi@yahoo.com.br
}

Submetido em 12/11/2011

Aceito para publicação em 14/07/2012

\section{Resumo}

Miíases são doenças parasitárias comuns em animais de produção. No Brasil, o parasitismo é conhecido, popularmente, como "bicheira" e "berne", de acordo com a apresentação clínica da doença e de seu agente etiológico. O estudo objetivou registrar o imaginário de uma população rural do município de Formosa (estado de Goiás) em relação às miíases em humanos e animais domésticos, com ênfase em bovinos. Entre 2009 e 2010 foram realizadas entrevistas semiestruturadas com 50 produtores rurais, abordando questões sobre as doenças e seus agentes etiológicos, o ciclo biológico das espécies de parasitas e os métodos empregados no tratamento segundo as tradições locais. Os entrevistados reconheceram as "bicheiras", apresentando um rico repertório de denominações aos seus agentes etiológicos e conhecendo muitas das etapas do ciclo biológico dos mesmos. Para o "berne", no entanto, o conhecimento dos produtores rurais foi escasso e algumas vezes até o parasitismo era desconhecido. A pesquisa salienta ainda a influência do sincretismo religioso e conhecimento popular no tratamento e manejo das mí́ases em animais e humanos.

Palavras-Chave: Cerrado; Cochliomyia hominivorax; Dermatobia hominis; Etnoparasitologia; Tradição rural

\section{Abstract}

Myiasis in the imagination of a rural population in Formosa (Goiás), Brazil. Myiases are common parasitic diseases found in livestock. In Brazil, these parasitosis are popularly known as bicheira and berne according to their clinical symptoms and etiological agents. The goal of this study was to record what is known by a rural population, in Formosa (Goiás State), about myiasis in humans and domestic animals, especially cattle. Between 2009 and 2010, semi-structured interviews were conducted with 50 farmers, who answered questions about the diseases and their etiological agents, the life cycle of the parasitic species and the treatment methods used according to local traditions. The interviewees recognized the bicheiras, providing a rich repertoire of 
names for their etiological agents, and they knew many of the steps of their biological cycle. However, this kind of comprehensive knowledge was not known for berne; in some cases even the parasite was unknown. This research also highlights the influence of religious syncretism and popular knowledge in the treatment and management of myiasis in animals and humans.

Key words: Cerrado; Cochliomyia hominivorax; Dermatobia hominis; Ethnoparasitology; Rural tradition

\section{Introdução}

A domesticação dos animais iniciou-se há aproximadamente 12.000 anos a.C., sendo os cães os primeiros animais domesticados pelo homem (GUPTA, 2004). Esse processo trouxe novidades que levariam a mudanças evolutivas tanto nos homens quanto nos animais, e em suas relações interespecíficas (DIAMOND, 2002; 2005). Uma das principais mudanças foi o incremento das doenças oriundas dos animais, denominadas, pelo patologista Rudolph Virchow, Zoonoses (SWABE, 1999; SIANTO et al., 2009). Essas moléstias tiveram papel importante para as alterações drásticas na sociedade humana, preenchendo o imaginário cultural com novos símbolos e mitos.

As enfermidades parasitárias são as mais ricas em construções simbólicas e míticas (WAGUESPACK, 2002; GURGEL-GONÇALVES, 2009). Essa peculiaridade associa-se à dificuldade de decifrar os complexos ciclos dos parasitos, às diferentes formas de manifestações das doenças e ao aspecto macroscópico e microscópico de alguns agentes etiológicos (MELLO et al., 1988). Entre as formas de parasitismo, o ectoparasitismo é um dos mais ricos em simbologia devido à exposição da enfermidade e até mesmo ao desconhecimento dos parasitas, compondo um dos mais importantes temas abordados pela etnoparasitologia (ARAÚJO et al., 2000). O ectoparasitismo está presente em vários contos e preenche o imaginário, principalmente, por ser facilmente verificável a olho desarmado (olho nu) e possuir distribuição global (LENKO; PAPAVERO, 1996).

A etnoparasitologia estuda os conhecimentos tradicionais sobre a biologia dos parasitos e o modo como as populações humanas lidam com as doenças parasitárias. A obtenção e a utilização pelos cientistas destes saberes populares podem trazer informações valiosas a respeito do tratamento e controle das enfermidades (GURGEL-GONÇALVES et al., 2007;
2009). No mesmo contexto, o parasitismo pode ser compreendido pela etnoveterinária que estuda os conhecimentos populares sobre a saúde animal, descrevendo as terapêuticas e agentes (minerais, flora ou fauna) utilizados na busca da cura de moléstias em animais (MATHIAS-MUNDY; McCORKLE, 1989; McCORKLE et al., 1996; FAROOQ et al., 2008; LANS et al., 2009).

Entre as ectoparasitoses destacam-se as míases pelas peculiaridades do ciclo biológico das moscas adultas e pela importância econômica e sanitária (LENKO; PAPAVERO, 1996; GUIMARÃES; PAPAVERO, 1999). As miĺases podem ser definidas como infestações ectoparasitárias de vertebrados vivos por larvas de Diptera que se alimentam, pelo menos durante parte da sua vida, do tecido vivo ou morto do seu hospedeiro, de suas substâncias corporais líquidas, ou do alimento por ele ingerido (ZUMPT, 1965). No Brasil são popularmente conhecidas como "bicheiras" e "bernes", de acordo com a apresentação clínica da doença e seus agentes etiológicos (GUIMARÃES; PAPAVERO, 1999), sendo consideradas entre os principais problemas da pecuária na América Latina, com perdas econômicas significativas na produção de leite, carne e indústria do couro (MOYA BORJA, 2003). Além disso, as miíases podem provocar danos relevantes em humanos, apresentando interesse em saúde pública no Brasil (GOMEZ et al., 2003; NASCIMENTO et al., 2005, FERNANDES et al., 2009). Os dois mais importantes dípteros parasitas na América do Sul são Dermatobia hominis L.f. e Cochliomyia hominivorax Coquerel (GUIMARÃES; PAPAVERO, 1999).

As peculiaridades do ciclo biológico das moscas, assim como a importância econômica e sanitária das miíases podem enriquecer o imaginário popular com diversos enigmas preenchidos por lendas e mitos locais (LENKO; PAPAVERO, 1996). Dessa forma, este 
estudo tem como objetivo registrar o imaginário de uma população rural do município de Formosa (Goiás) em relação às miíases em humanos e animais domésticos. Este trabalho relata as definições da doença e seus agentes etiológicos, o ciclo biológico das espécies de parasitas e os métodos empregados no tratamento segundo as tradições locais. Além disso, descreve a percepção dos produtores rurais de Formosa sobre as relações entre hospedeiros e parasitas.

\section{Material e Métodos}

Entre junho de 2009 e junho de 2010 foram realizadas entrevistas semiestruturadas sobre o conhecimento das miíases em uma população rural do município de Formosa ( $15^{\circ} 32$ 'S e $47^{\circ} 20^{\prime}$ O), localizado na região nordeste do estado de Goiás, Brasil.

Formosa é um dos municípios típicos do estado de Goiás cuja economia está pautada na produção agropecuária, principalmente a criação de gado. Surgiu em meados do século XVIII, com o povoado inicialmente batizado de Arraial do Couro em homenagem aos viajantes que acampavam no local em barracas de couro que eles traziam para comercializar. Sua formação étnica é composta principalmente de negros e mestiços e a forte presença da religiosidade, de origem Europeia e Africana, garantem uma rica diversidade cultural permeadas de crenças e mitos (LOBO; BERNARDES, 2006).

As entrevistas foram pautadas em um formulário com questões sobre a definição da doença, o agente etiológico, principais hospedeiros e suas características, período de maior ocorrência, ação sobre humanos (zoonose), tratamento (cura), biologia das moscas adultas e seu controle. Nas questões sobre o tratamento foi verificado se a enfermidade pode ser ou não tratada, os métodos e sua aplicação tradicional, dentro de três abordagens - mágico-religiosa, utilização de plantas ou partes de vegetais e medicamentos alopáticos ou produtos químicos. A denominação "berne" e "bicheira" foi utilizada na entrevista e apresentação dos resultados para facilitar a compreensão do conhecimento local.

As plantas que foram citadas pelos entrevistados foram identificadas in loco com a presença de botânico no dia das entrevistas.
Durante a pesquisa foram entrevistadas 50 pessoas em uma área de assentamento rural em Formosa, de ambos os sexos, nativos da região, com idade entre 25 a 70 anos. A pesquisa buscava o conhecimento regional dos produtores independente de idade ou sexo. Dessa forma, proprietários de pequena propriedade rural com predomínio da produção de gado foram entrevistados. O nível educacional era de ensino fundamental a médio. Todos foram entrevistados em suas propriedades. As entrevistas foram filmadas, entretanto antes de qualquer entrevista e filmagem era solicitado aos entrevistados o preenchimento de uma ficha de livre consentimento para captura de imagens e sons. As entrevistas foram analisadas posteriormente em relação à predominância e à diversidade de informações. Além do formulário, para cada um dos entrevistados da pesquisa apresentou-se as duas moscas das espécies causadoras das miíases na região foco do questionário (Cochliomyia hominivorax e Dermatobia hominis) sem a denominação prévia para verificar o conhecimento das pessoas sobre o nome, características biológicas, ocorrência e se podia ou não causar outros tipos de doenças em humanos. As coletas de dados foram realizadas mensalmente, com quatro a cinco entrevistas mensais, que ocorreram nos primeiros finais de semana do mês. A entrevista no final de semana foi escolhida por ser o período que os produtores estão mais receptivos a visitas.

As entrevistas foram transcritas e a análise dos dados foi realizada a partir de tabelas de cognição comparada, que equipararam o conhecimento dos entrevistados com informações sobre as miíases obtidas na literatura (ZUMPT, 1965; HALL; WALL, 1995; LENKO; PAPAVERO, 1996; GUIMARÃES; PAPAVERO, 1999; EVANS; FACCINI, 2000; COLWELL et al., 2006). Todos os materiais etnográficos estão mantidos no Laboratório de Dipterologia e Entomologia Forense da Universidade de Brasília e cópias editadas na Biblioteca Central da UnB.

\section{Resultados}

Em relação ao parasitismo ocasionado pelas larvas de $C$. hominivorax, todos os entrevistados a reconheceram como "bicheira" $(\mathrm{N}=50)$. A maior parte dos entrevistados 
(86\%) considerou a bicheira um problema sério e frequente para a pecuária bovina na região. A bicheira foi reconhecida como uma enfermidade ocasionada por uma mosca, considerada larvípara por $92 \%$ dos entrevistados e ovípara pelos demais (4\%). Para a maioria das pessoas questionadas é necessária uma ferida prévia (96\%), as demais não sabiam como ocorre. As principais formas e tipos de ferimentos citados foram arranhões, tratamento incorreto do umbigo dos bezerros, mordidas de morcego, ferimentos abrasivos, alta infestação de carrapatos e a lesões devido à presença do berne. Os atrativos citados para a mosca causadora da bicheira foram: sangue, ferida, ferimento sangrando, gado doente e machucado, muito carrapato, mela do chupão de morcego, picada de cobra, tumor e furúnculo do berne. Para alguns entrevistados que consideraram as moscas ovíparas, os ovos foram denominados como vareja, varejeira e ovo. As larvas recebem os nomes de varejeira, vareja, berno, bicho, bicheira e larva. Apenas uma pessoa considerou o agente da bicheira como sendo bactérias depositadas pela mosca, entretanto não houve questionamento sobre as considerações e conhecimento do que o entrevistado denomina como bactéria.

Quando questionados sobre o parasitismo por $D$. hominis, 96\% dos entrevistados reconheceu como berne. Porém os nativos não o consideram como um problema para a pecuária local $(86 \%)$. Essa mosca foi reconhecida predominantemente como larvípara (70\%). Os nomes populares citados para o ovo do berne foram lêndea e ovo; para as larvas, foram: berne, berno, feto, coró, larva, larva cabeluda.

A forma de transmissão predominantemente citada para o berne foi o depósito direto da larva ou ovo no hospedeiro pela mosca, sem a necessidade de ferida (78\%). Dentro desta forma de transmissão houve duas respostas diferentes obtidas, uma com a picada da mosca, correspondendo a $28 \%$, e outra apenas com o contato com o hospedeiro (72\%). Em relação à transmissão não direta, dois entrevistados (4\%) identificaram a transferência dos parasitas a partir do depósito das larvas ou ovos pela mosca nas folhas de arbustos ou árvores, e o hospedeiro é infestado pelo contato com as plantas. $\mathrm{O}$ uso de um inseto transportador (forético) foi citado apenas por um produtor. O desconhecimento total da biologia parasitária foi de $16 \%(\mathrm{~N}=8)$. Os atrativos relatados para a mosca desta moléstia foram o suor, odor, calor e até mesmo feridas.

Em relação aos agentes etiológicos da bicheira e berne, $80 \%$ dos entrevistados consideraram que a bicheira e o berne são oriundos de moscas diferentes, $4 \%$ acharam que eram a mesma espécie e $16 \%$ não sabiam.

Quando questionados sobre o período de maior ocorrência para as miíases, verificou-se que a bicheira é popularmente mais observada na estação chuvosa (70\%), ao contrário do berne, com maior ocorrência na estação seca (36\%).

Sobre os hospedeiros, os entrevistados consideraram a espécie bovina mais susceptível ao berne $(62 \%, \mathrm{~N}=31)$ e à bicheira $(70 \%, \mathrm{~N}=35)$, embora outras espécies tenham sido mencionadas (Tabela 1). As principais características do hospedeiro do berne são animais de qualquer idade e de pelagem escura, enquanto que para a bicheira parece não haver distinção de idade ou cor da pelagem segundo os produtores (Tabela 1). Para eles, humanos raramente são infestados por bicheiras $(10 \%$, $\mathrm{N}=5$ ), porém o berne foi em outros tempos uma doença comum nas pessoas que trabalhavam na pecuária $(88 \%$, $\mathrm{N}=44$ ), sendo praticamente inexistente na atualidade.

Os principais produtos farmacêuticos e químicos, todos com os nomes comerciais mencionados, foram os mata bicheiras, de várias apresentações comerciais (Lepecid ${ }^{\circledR}$ e outros), creosoto $\left(\right.$ Creolina $\left.^{\circledR}\right)$, Avermectinas $\left(\right.$ Dectomax $^{\circledR}$, Ivomec $\left.^{\circledR}\right)$, Fentione $\left(\right.$ Tiguvon $\left.^{\circledR}\right)$, Triclorfone $\left(\right.$ Neguvon $\left.^{\circledR}\right)$, Coumafós $\left(\right.$ Tanidil $\left.{ }^{\circledR}\right)$ e Piretróide $\left(\right.$ Barrage $\left.^{\circledR}\right)$. Até mesmo antibióticos, como a oxitetraciclina, foram citados por dois entrevistados no combate à miíase. A associação entre produtos era a forma mais comumente referida $(70 \%)$. A Creolina ${ }^{\circledR}$ com o mata bicheira era a associação mais frequente (36\%). Outras formas citadas foram o óleo diesel queimado e Neguvon ${ }^{\circledR}$, Ivermectina junto com mata bicheira, o conjunto de iodo, mata bicheira e Creolina ${ }^{\circledR}$. Para o berne as seguintes apresentações comerciais e farmacológicas foram citadas: mata bicheira Lepecid $^{\circledR}$ e outros, Creolina ${ }^{\circledR}$, Dectomax $^{\circledR}$, Ivomec ${ }^{\circledR}$, Fipronil $^{\circledR}$, Neguvon ${ }^{\circledR}$, Barrage $^{\circledR}$. As associações foram menos frequentes (36\%), sendo que $18 \%$ da população não conheciam nenhuma forma 
de tratamento. A associação mais comum descrita foi Neguvon ${ }^{\circledR}$ e óleo lubrificante de motor reutilizado.

TABELA 1: Características dos hospedeiros do berne e bicheira, segundo o conhecimento tradicional dos produtores rurais entrevistados em Formosa, Goiás, Brasil, 2010.

\begin{tabular}{lcccc}
\hline \multirow{2}{*}{ Características } & \multicolumn{3}{c}{ Berne } & \multicolumn{3}{c}{ Bicheira } \\
\cline { 2 - 5 } Principal hospedeiro & $\mathbf{N}$ & $\%$ & $\mathbf{N}$ & $\%$ \\
Bovino & 31 & 62 & 35 & 70 \\
Equino & 1 & 2 & 4 & 8 \\
Cachorro & 2 & 4 & 0 & 0 \\
Porco & 0 & 0 & 1 & 2 \\
Sem preferência & 6 & 12 & 9 & 18 \\
Não sabe informar & 10 & 20 & 1 & 2 \\
Idade do hospedeiro & & & & \\
Adulto & 0 & 0 & 2 & 4 \\
Filhote & 3 & 6 & 5 & 10 \\
Velho & 5 & 10 & 5 & 10 \\
Qualquer idade & 35 & 70 & 36 & 72 \\
Não sabe informar & 7 & 14 & 2 & 4 \\
Cor da pelagem do hospedeiro & & & & \\
Escura & 28 & 56 & 20 & 40 \\
Clara & 0 & 0 & 0 & 0 \\
Sem preferência & 11 & 22 & 22 & 44 \\
Não sabe informar & 11 & 22 & 8 & 16 \\
\hline
\end{tabular}

Plantas e suas partes processadas ou in natura são muito utilizadas na região para tratar principalmente bicheiras, uma vez que $48 \%$ dos entrevistados conheciam e utilizavam alguma espécie de planta para tratar as feridas ou para matar as larvas; já para o berne o uso não foi muito comum (10\%). As principais plantas recomendadas contra bicheiras citadas, principalmente para cicatrizar as feridas, foram: pacari ou dedaleiro (Lafoensia pacari St.-Hil.), barbatimão (Stryphnodendron barbatiman Mart.), goiabeira (Psidium guajava L.), carrapicho (Desmodium adscendens DC.), caldo de feijão cozido (Phaseolus vulgaris L.), jenipapeiro (Genipa americana L.), açafrão em pó (Curcuma longa L.), unha-de-anta ou pata-de-vaca (Bauhinia candicans Benth.), algodão (Gossypium spp. L.) e nim (Azadirachta indica Juss.). Esses recursos vegetais são utilizados na forma de banhos ou compressas nos animais feridos, utilizando os frutos no caso de jenipapeiro e carrapicho, folhas e caules nos demais. O pacari e barbatimão são vegetais lenhosos usados diretamente na lesão para cicatrizar, colocando-se raspas da casca no lugar afetado, sendo de uso mais comum que as demais plantas. As folhas e casca de nim seca moídas são adicionadas, segundo um dos produtores, ao sal de consumo do gado. $\mathrm{O}$ açafrão era utilizado o pó processado de uso na culinária.

No caso do berne apenas quatro recursos foram citados: o leite da seringueira (Hevea brasiliensis L.) de uso direto no furúnculo; dente de alho picado (Allium sativum L.) junto com cinzas e aplicado ao sal; a água das folhas de tabaco (Nicotiana tabacum L.) para banhar os bovinos; e o nim de uso semelhante ao apresentado para as bicheiras.

A religiosidade e o misticismo foram citados entre os principais componentes na tentativa de tratamento das mí́ases em Formosa, pois $84 \%$ dos entrevistados mencionaram que conhecem o uso de simpatia, reza ou benzimento para matar a bicheira, mas apenas $42 \%$ usaram ou solicitaram a ajuda de um (a) rezador (a) para tratar seus animais. Apenas três produtores rurais expuseram a forma como faziam a cura e relataram as simpatias. Abaixo são transcritas as duas simpatias registradas:

"Quando não dá para curar o animal com creolina, por falta de creolina, de companhia (ajuda) ou falta de laço, a pessoa localiza o animal, onde ele está, localiza o pé esquerdo traseiro do gado. Aí, sem palavras, ele pega duas folhas de capim, qualquer capim, e uma pedra. Atira a pedra no chão e faz a cruz em cima do pé esquerdo do animal e põe a pedra em cima com a barriga para cima, ou seja, com a parte que estava apoiada no chão coloca para cima e nada mais e nada menos. Daqui três dias pode procurar o animal que não tem nenhum bicho na ferida, cai tudo!" (B.F.M., 65 anos).

"Se o animal vai correndo, você pega o rasto dele com uma faca e corta uma folha verde certinho da pegada e põe em cima, aí cai tudo em poucos dias" (J.S., 38 anos).

As benzeduras registradas durante as entrevistas foram:

"Tem outra que tanto faz ver o animal ou não, eu pego três folhinhas de ramo qualquer ou capim, faço um nó e giro, de preferência começando do nascer do sol e indo pela direita até completar o ciclo. Ai eu digo três vezes: - Bicheira, a partir de hoje você irá em frente como os serviços trabalhados no domingo. Usando os três capins ou ramos, três dias depois cai tudo" (B.F.M., 65 anos). 
"Pelo nome do Pai, Filho e Espírito Santo, eu creio em três palavras na virgem Santa Maria. Jesus me abençoa e só ele que possa fazer seguramente desta bicheira, os bichos têm que cair de um, a dois, a três, a quatro, a cinco, a seis, a sete. Creio em Deus, Pai dos filhos e de todos os santos, pois estas bicheiras não são de arrimo, estes bichos hão de cair de um, a dois, a três, a quatro, a cinco, a seis, a sete. Eu Rezo três vezes seguida. Depois eu louvo a Deus, pois é ele quem cura, eu não curo nada" (B.P.G., 70 anos).

"Se serviço de domingo e dia santo for acima mesmo assim você desvirtua esta bicheira, pelo nome do Pai, Filho e Espírito Santo'. Eu tenho que falar três vezes seguido" (B.P.G., 70 anos).

Ao apresentar e solicitar o conhecimento dos entrevistados em relação às moscas da coleção, diversos nomes foram dados a espécie Dermatobia hominis e para espécie $C$. hominivorax (Tabela 2). C. hominivorax é a espécie mais conhecida (88\%), e quase sempre reconhecida como causadora da bicheira.

TABELA 2: Nomes comuns citados para as espécies de Diptera apresentadas aos produtores rurais de Formosa, Goiás, Brasil, durante aplicação do formulário etnobiológico sobre miíases na região. Formosa, 2010.

\begin{tabular}{lcccc}
\hline \multirow{2}{*}{ NOMES CITADOS } & \multicolumn{2}{c}{$\begin{array}{c}\text { Dermatobia } \\
\text { hominis }\end{array}$} & \multicolumn{2}{c}{$\begin{array}{c}\text { Cochliomyia } \\
\text { hominivorax }\end{array}$} \\
\cline { 2 - 5 } & $\mathbf{N}$ & $\mathbf{\%}$ & $\mathbf{N}$ & $\%$ \\
\hline Mutuca & 5 & 10 & 0 & 0 \\
Berneira & 16 & 32 & 1 & 2 \\
Varejeira ou Vareja & 6 & 12 & 21 & 42 \\
Mosca-azul & 0 & 0 & 4 & 8 \\
Mosca-da-bicheira & 0 & 0 & 16 & 32 \\
Mosquitão & 1 & 2 & 0 & 0 \\
Mosca-do-chifre & 2 & 4 & 0 & 0 \\
Mosca-caseira & 0 & 0 & 2 & 4 \\
Não conhece & 20 & 40 & 6 & 12 \\
\hline
\end{tabular}

Os entrevistados dessa zona rural de Formosa identificam diversos locais onde vivem ou permanecem os insetos causadores de mí́ases, como as matas, pastagens sujas, chiqueiros, currais, cerrado, esgoto, no próprio animal (gado), nas casas, fezes, pé de serra e montanhas e lugares sujos.

Quando questionados sobre a biologia das moscas, apenas uma pessoa soube dizer como as moscas nasciam. Em relação às outras características, como alimentação, ninguém soube responder. De acordo com os entrevistados, as espécies de moscas são abundantes na região ( $82 \%)$, principalmente no período das chuvas (50\%). A maioria desconheceu qualquer outra doença que estes insetos possam transmitir (Tabela 3).

TABELA 3: Porcentagem das respostas sobre a descrição das características biológicas das moscas adultas segundo o imaginário dos produtores rurais de Formosa, Goiás, Brasil.

\begin{tabular}{|c|c|c|c|c|c|c|}
\hline \multirow{2}{*}{ PERGUNTAS } & \multicolumn{2}{|c|}{ SIM } & \multicolumn{2}{|c|}{ NÃO } & \multicolumn{2}{|c|}{ NSI* } \\
\hline & $\mathbf{N}$ & $\%$ & $\mathbf{N}$ & $\%$ & $\mathbf{N}$ & $\%$ \\
\hline Sabe como as moscas nascem? & 1 & 2 & 49 & 98 & - & - \\
\hline Sabe do que e & 0 & 0 & 50 & 100 & - & - \\
\hline Existem na sua região? & 41 & 82 & 6 & 12 & 3 & 6 \\
\hline $\begin{array}{l}\text { Elas podem transmitir outras } \\
\text { doenças além das bicheiras e bernes? }\end{array}$ & 9 & 18 & 0 & 0 & 41 & 82 \\
\hline
\end{tabular}

*NSI - Não sabe informar

\section{Discussão}

No presente estudo verificou-se que bicheira e berne são comumente conhecidas pelos produtores, pois a pecuária bovina é a atividade econômica predominante na região. As miíases estão entre os maiores problemas parasitários na pecuária, devido à resistência ao tratamento e por causar perdas significativas no peso dos animais e na qualidade do couro, como já verificado em outras localidades do Brasil (SANAVRIA et al., 2002; MOYA BORJA, 2003).

A relação cultural é mais forte para as bicheiras, com conhecimento detalhado do ciclo de $C$. hominivorax. Apesar dos entrevistados não identificarem o agente etiológico da enfermidade em todas as suas características, reconhecem algumas espécies da família Calliphoridae, denominado-as como varejeiras ou mosca-da-bicheira. Os entrevistados sempre associam a bicheira como resultante de ferimentos diversos como atrativo para as moscas. Esse conhecimento tradicional é confirmado pela ciência, a qual demonstra a necessidade de um ferimento e o odor destas feridas oriundas de diversas bactérias como atrativo para as fêmeas de $C$. hominivorax realizarem a oviposição (CORK; HALL, 2007; CHAUDHURY et al., 2010). 
O berne, miíase causada por $D$. hominis, é uma doença enigmática para a população local, principalmente pela complexidade do ciclo, com a necessidade de um animal transportador para completá-lo (LENKO; PAPAVERO, 1996; EVANS; FACCINI, 2000). A mosca do berne possui as peças bucais atrofiadas nos adultos, por isso elas não se alimentam (GUIMARÃES; PAPAVERO, 1999). Estas características, assim como a necessidade de um animal transportador, são completamente desconhecidas para os indivíduos questionados, favorecendo o florescimento de crendices de transmissões, até por outras espécies, entre elas o Syrphidae Ornidia obesa, como citam Lenko e Papavero (1996).

A larviposição realizada pelos insetos descritos pela maioria dos entrevistados pode ser oriunda da errônea interpretação resultante da repulsa e a classificação de inferioridade destes animais pela cultura regional (COSTA NETO, 2002; COSTA NETO; MAGALHÃES, 2007). Esta aversão às moscas talvez não possibilite que a população local possa aprofundar no conhecimento da biologia, entre elas a própria metamorfose completa do inseto. Muitas vezes isso ocorre porque o produtor somente observa as lesões quando há presença de larvas de segundo ou terceiro ínstares.

Outra hipótese é a presença de outros parasitas causadores de mí́ases na região que são larvíparas, uma vez que os habitantes não reconhecem ou confundem as moscas adultas, entre as quais estão os Sarcophagidae, díptera larvíparo que causa miíase facultativa e secundária em homens e outros animais em quase todos os continentes (ZUMPT, 1965; HALL; WALL, 1995). A oviposição é raramente considerada, muitas vezes pela dificuldade de observar os ovos na ferida.

Os nomes conhecidos localmente para as larvas e ovos já foram descritos na literatura (LENKO; PAPAVERO, 1996; GUIMARÃES; PAPAVERO, 1999). O conhecimento tradicional sobre a periodicidade das bicheiras no cerrado é semelhante ao conhecimento científico sobre a incidência de miíases (GUIMARÃES; PAPAVERO, 1999), cuja estação predominante é a chuvosa, fato associado à necessidade de calor e umidade para realização da pupação de $C$. hominivorax. A mesma associação não foi verificada para a ocorrência de berne. Esta espécie também necessita de um ambiente favorável em temperatura e umidade, e a disposição de solo macio para a pupação, características verificadas apenas na estação chuvosa (BRITO; MOYA BORJA, 2000; SANAVRIA et al., 2002). No presente estudo as pessoas reportaram uma maior ocorrência de berne na estação seca no cerrado.

Sobre os hospedeiros, foi registrada a predominância das miíases em bovinos. Este relato é aceitável pelo imenso rebanho local, descaracterizando a importância desta doença nas outras espécies. As características de escolha do hospedeiro correspondem à literatura científica, em relação a cor da pelagem, sexo e idade (EVANS; FACCINI, 2000; SANAVRIA et al., 2002).

As bicheiras em humanos são geralmente associadas ao descuido com a higiene, ocorrendo em pessoas debilitadas por doenças crônicas (AIDS, diabetes, lúpus e outras), toxicomaníacos ou distúrbios psiquiátricos (GOMEZ et al., 2003; NASCIMENTO et al., 2005; FERNANDES et al., 2009), por isso a raridade nos relatos nas entrevistas. A ocorrência, segundo a população rural, é por causa da falta de higiene. Já o berne era um achado comum em Formosa, entretanto atualmente os achados são raros. Esta parasitose é frequente em produtores rurais e turistas em outras áreas da América do Sul (LEITE; EVANGELISTA, 2002; CLYTI et al., 2007).

O imaginário cultural considera os adjuvantes, substâncias adicionadas aos medicamentos para facilitar absorção, como os reais agentes terapêuticos, julgando a eficácia terapêutica do fármaco inútil sem a adição destas substâncias. O despreparo no uso dos medicamentos é visível na dosagem e via de uso dos fármacos, exemplificado com a creolina de uso indiscriminado não seguindo as recomendações da bula. Os produtos mais usados para bicheira são da família química dos Piretróides e Organofosforados, agentes mais baratos e encontrados com facilidade no comércio local. As utilizações indiscriminadas em todas as formas geram dois problemas, geralmente desconsiderados pelos proprietários dos animais: a resistência do parasito ao químico e a intoxicação dos animais (VERCRUYSSE; REW 2002; ANADÓN et al., 2009) 
As plantas e suas partes in natura ou processadas sempre foram uma alternativa para as regiões mais remotas, onde a assistência técnica é precária ou ausente, e também onde o tradicionalismo é arraigado (McCORCKLE et al., 1996; LANS; BROWN, 1998). Verificou-se que o uso de fitoterápicos, apesar de conhecido pela maioria, é parcamente usufruído. Muitas dessas plantas, como o pacari e o barbatimão, são usadas para funções descontextualizadas com o conhecimento científico. Estes dois vegetais são comprovadamente de ação antiinflamatória (GUIMARÃES et al., 2010), conquanto na tradição local eles podem matar as larvas. Das plantas citadas apenas duas têm ação antiparasitária comprovada: L. pacari $\mathrm{e}$ A indica, sendo que a primeira contra toxocaríase em animais e a segunda contra ectoparasitoses. Destas, apenas L. pacari é nativa do cerrado (ROGÉRIO et al., 2003; DELEITO; MOYA BORJA, 2008). Os demais vegetais relatados não possuem estudos sobre sua utilização.

A religiosidade e o misticismo é outra vertente de amplo uso para combater a míase em Formosa. Isto é justificado pela formação religiosa na região, com forte influência cristã e das religiões africanas (LOBO; BERNARDES, 2006) e a ausência da assistência técnica. Verificamos que o benzimento ou simpatia é de conhecimento da maioria dos entrevistados; o uso, porém, é limitado por outras crenças ou pela acessibilidade aos benzedores.

As benzeduras expostas são inéditas quando comparadas à obra descritiva de Lenko e Papavero (1996). Contudo, possuem os mesmos tabus e limitantes originados dos dogmas religiosos e outros do misticismo. Respeitar o domingo, não trabalhando ou realizando benzeduras, não benzer animais por meio de rios ou lagos, não cobrar pela reza são alguns dos tabus. As benzeduras obtidas em nosso estudo na região Centro-Oeste possuem as mesmas composições místicas relatadas no trabalho de Lenko e Papavero (1996) para diversas regiões brasileiras e outras partes do mundo. Estas composições muitas vezes estão associadas à crença da energia natural nos objetos, principalmente agentes naturais, como partes de plantas, pedras e até mesmo o rastro dos animais.

O misticismo ligado a esses objetos e eventos representa a força para a cicatrização da ferida e queda das larvas, situação comum em quase todas as simpatias citadas por Lenko e Papavero (1996). Outra situação inusitada da ação mística das simpatias e benzimentos é sua relação da rima com números sequenciais, que representam a queda dos bichos, em sua grande maioria estes números são três ou ímpares. Porém, a relação desta crença com o ciclo do parasitismo ou qualquer outro fato científico é desconhecida.

Em relação às espécies de moscas apresentadas aos entrevistados para identificação e caracterização popular, apenas $C$. hominivorax foi reconhecida pela maioria como responsável por causar a bicheira, e denominada de mosca-da-bicheira ou varejeira. A atual ausência dos casos de berne em animais domésticos e em humanos justifica o desconhecimento do parasito $D$. hominis. Além disso, os adultos desta espécie raramente são vistos já que utilizam um forético para conduzir suas larvas ao hospedeiro (GUIMARÃES; PAPAVERO, 1999; EVANS; FACCINI, 2000).

Este trabalho descritivo apresenta situações dualísticas entre ciência e tradições. Em certos momentos as entrevistas apresentaram situações em que há um grande abismo entre o conhecimento científico e a cultura local; outras vezes, as duas percepções estão concatenadas. A crendice e os tabus no tratamento das bicheiras e dos bernes prevalecem muitas vezes por falta de assistência técnica na região e à inacessibilidade ao conhecimento científico. Segundo Gurung (2003), a cultura popular e os cientistas devem estar compassados em um único ideal, e principalmente a ciência deve ser acessível a todos.

\section{Agradecimentos}

Ao professor Nelson Papavero pelas críticas orientações em diferentes partes deste trabalho. Os autores ERC, RGG e JRPL agradecem as seguintes agências de fomento à pesquisa: Conselho Nacional de Desenvolvimento Científico e Tecnológico (CNPq); Coordenação de Aperfeiçoamento de Pessoal de Nível Superior (CAPES); Fundação de Apoio à Pesquisa do Distrito Federal (FAPDF); Fundação de Âmparo à Pesquisa do Estado de São Paulo (FAPESP); Financiadora de Estudos e Projetos (FINEP) e ao Programa de Pós- 
graduação em Biologia Animal da Universidade de Brasília. Agradecemos especialmente à população de Formosa, Estado de Goiás, pela disponibilidade e receptividade em todas as etapas deste trabalho.

\section{Referências}

ANADÓN, A.; MARTÍNEZ-LARRANÃGA, M. R.; MARTÍNEZ, M. A. Use and abuse of pyrethrins and synthetic pyrethroids in veterinary medicine. The Veterinary Journal, London, v. 182, p. 7-20, 2009.

ARAÚJO, A.; FERREIRA, L. F.; GUIDON, N.; FREIRE, N. M. S.; REINHARD, K.; DITTMAR, K. Ten thousand years of head lice infection. Parasitology Today, Cambridge, v. 7, p. 269, 2000.

BRITO, L. G.; MOYA BORJA, G. E. Seasonal fluctuation of Dermatobia hominis in bovine skins from a slaughterhouse. Pesquisa Veterinária Brasileira, Rio de Janeiro, v. 20, n. 4, p. 151-154, 2000.

CHAUDHURY, M. F.; SKODA, S. R.; SAGEL, A.; WELCH, J. B. Volatiles emitted from eight wound-isolated bacteria differentially attract gravid screwworms (Diptera: Calliphoridae) to oviposit. Journal of Medical Entomology, London, v. 47, n. 3, p. 349-354, 2010.

CLYTI, E.; NACHER, M.; MERRIEN, L.; EL GUEDJ, M.; ROUSSEL, M.; SAINTE-MARIE, D.; COUPPIÉ, P. Myiasis owing to Dermatobia hominis in a HIV-infected subject: Treatment by topical Ivermectin. International Journal of Dermatology, Philadelphia, v. 46, p. 52-54, 2007.

COLWELL D. D.; HALL, M. J. R.; SCHOLL, P. J. The oestrid flies: biology, host parasite relationships, impact and management. Oxfordshire: CAB international, 2006. 359 p.

CORK, A.; HALL, M. J. R. Development of an odour-baited target for female New World screwworm, Cochliomyia hominivorax: studies with host baits and synthetic wound fluids. Medical and Veterinary Entomology, London, v. 21, p. 85-92, 2007.

COSTA NETO, E. M. Manual de Etnoentomología. Zaragoza: Manuales y Tesis SEA, 2002. 104 p.

COSTA NETO, E. M.; MAGALHÃES, H. F. The ethnocategory "insect" in the conception of the inhabitants of Tapera County, São Gonçalo dos Campos, Bahia, Brazil. Anais da Academia Brasileira de Ciências, São Paulo, v. 79, n. 2, p. 239-249, 2007.

DELEITO, C. S. R.; MOYA BORJA, G. E. Neem (Azadirachta indica): An alternative for controlling flies associated with animal breeding. Pesquisa Veterinária Brasileira, Rio de Janeiro, v. 28, n. 6, p. 293-298, 2008

DIAMOND, J. Evolution, consequences and future of plant and animal domestication. Nature, London, v. 418, p. 700-707, 2002.

DIAMOND, J. Guns, germs and steel: the fates of human societies. 2. ed. New York: W.W. Norton and Company, 2005. 496 p.

EVANS, D. E.; FACCINI, J. L. H. Dermatobia hominis (Linnaeus Jr., 1781) (Diptera, Cuterebridae): intriguing insect, impressive pest, continuing enigmas. Contribuições Avulsas sobre História Natural Brasileira, Série Zoologia, São Paulo, v. 15, p. 1-5, 2000.
FAROOQ, Z.; IQBAL, Z.; MUSHTAQ, S.; MUHAMMAD, G.; IQBAL M. Z.; ARSHAD, M. Ethnoveterinary practices for the treatment of parasitic diseases in livestock in Cholistan desert (Pakistan). Journal of Ethnopharmacology, Cagliari, v. 118, p. 213-219, 2008

FERNANDES, L. F.; PIMENTA, F. C.; FERNANDES, F. F. First report of human myiasis in Goiás state, Brazil: frequency of different types of myiasis, their various etiological agents, and associated factors. Journal of Parasitology, Lawrence, v. 95, n. 1, p. 32-38, 2009.

GOMEZ, R. S.; PERDIGÃO, P. F.; PIMENTA, F. J. G.; RIOS LEITE, A. C.; TANOS DE LACERDA, J. C.; CUSTÓDIO NETO, A. L. 2003. Oral myiasis by screwworm Cochliomyia hominivorax. British Journal of Oral and Maxillofacial Surgery, London, v. 41, p. 115-116, 2003.

GUIMARÃES, H. A.; NASCIMENTO, M. V. M.; TAVARES, A.; GALDINO, P. M.; PAULA, J. R.; COSTA, E. A. Effects of ethanolic extract of leaves of Lafoensia pacari A. St.-Hil., Lythraceae (pacari), in pain and inflammation models. Brazilian Journal of Pharmacognosy, João Pessoa, v. 20, n. 3, p. 328-333, 2010.

GUIMARÃES, J. H.; PAPAVERO N. Myiasis in man and animals in the Neotropical region. São Paulo: Pleiâde/FAPESP, 1999. 308 p. GUPTA, A. K. Origin of agriculture and domestication of plants and animals linked to early Holocene climate amelioration. Current Science, Bangalore, v. 87, n. 01, p. 54-59, 2004.

GURGEL-GONÇALVES, R. Etnoparasitología. In: COSTA NETO, E. M.; SILVA-FITA, D.; CLAVIJO, M. V. (Ed.). Manual de Etnozoología. Valencia: Tundra Ediciones, 2009. p. 176-199.

GURGEL-GONÇALVES, R.; MINUZZI-SOUZA, T. T. C.; COSTA NETO, E. M.; CUBA, C. A. C. O que é um parasito? Uma análise etimológica e semântica do termo parasito em diferentes idiomas. Acta Scientiarum Human and Social Sciences, Maringá, v. 29, n. 2, p. 151-161, 2007.

GURUNG, A. B. Insects - a mistake in God's creation? Tharu farmers' perception and knowledge of insects: A case study of Gobardiha Village Development Committee, Dang-Deukhuri, Nepal. Agriculture and Human Values, Gainesville, v. 20, p. $337-$ 370, 2003.

HALL, M.; WALL, R. Myiasis of human and domestic animals. Advances in Parasitology, London, v. 35, p. 257-334, 1995.

LANS, C.; BROWN, G. Ethnoveterinary medicines used for ruminants in Trinidad and Tobago. Preventive Veterinary Medicine, Bunbury, v. 35, p. 149-163, 1998.

LANS, C.; TURNER, N.; BRAUER, G.; KHAN, T. Medicinal plants used in British Columbia, Canada, for reproductive health in pets. Preventive Veterinary Medicine, Bunbury, v. 90, p. 268273, 2009.

LEITE, A. C. R.; EVANGELISTA, L. G. Activated host neutrophils in the larval midgut lumen of the human bot fly Dermatobia hominis. Tissue and Cell, New York, v. 34, n. 2, p. 98-102, 2002.

LENKO, K.; PAPAVERO, N. Insetos no Folclore. São Paulo: Plêiade/FAPESP, 1996. 468 p.

LOBO, J. M.; BERNARDES, M. A. Formosa em retinas idosas. Brasília: Alpha, 2006. 320 p.

MATHIAS-MUNDY E.; McCORKLE, M. C. Ethnoveterinary Medicine: an annotated bibliography. bibliographies in technology 
and social change. 1. ed. Iowa: Technology and Ames: Social Change Programme, IOWA State University, 1989. 361 p.

McCORKLE, C. M.; MATHIAS-MUNDY, E.; SCHILLHORN VAN VEEN. T. (Ed.). Ethnoveterinary research and development. London: IT Publications, 1996. 338 p.

MELLO, D. A.; PRIPAS, S.; FUCCI, M.; SANTORO, M. C.; PEDRAZZANI, E. S. Helmintoses intestinais I, Conhecimentos, atitudes e percepção da população. Revista de Saúde Pública, São Paulo, v. 22, p. 140-149, 1988.

MOYA BORJA, G. E. Erradicação ou manejo integrado das miíases neotropicais das Américas? Pesquisa Veterinária Brasileira, Rio de Janeiro, v. 32, p. 131-138, 2003.

NASCIMENTO, E. M. F.; OLIVEIRA, J. B.; PAES, M. J.; LOBO, A. P.; SILVA, A. L. A.; SANTOS, E. R.; LEAL, L. F.; MOYA BORJA, G. E. Míases humanas por Cochliomyia hominivorax (Coquerel, 1858) (Diptera: Calliphoridae) em hospitais públicos na cidade do Recife, Pernambuco, Brasil. Entomología y Vectores, Rio de Janeiro, v. 12, n. 1, p. 37-51, 2005.

ROGÉRIO, A. P.; SÁ-NUNES, A.; ALBUQUERQUE, D. A.; ANIBAL, F. F.; MEDEIROS, A. I.; MACHADO, E. R.; SOUZA, A. O.; PRADO JR., J. C.; FACCIOLI. L. H. Lafoensia pacari extract inhibits IL-5 production in toxocariasis. Parasite Immunology, Oxford, v. 25, p. 393-400, 2003.

SANAVRIA, A.; BARBOSA, C. G.; BEZERRA, E. S.; MORAIS, M. C.; GIUPPONI, P.C. Distribution and frequency of the larvae of the Dermatobia hominis (Linnaeus Jr., 1781) (Diptera: Cuterebridae) in cattle skin. Parasitologia Latinoamericana, Santiago, v. 57, p. 21-24, 2002.

SIANTO, L.; CHAME, M.; SILVA, C. S. P.; GONÇALVES, M. L. C.; REINHARD, K.; FUGASSA, M.; ARAÚJO, A. Animal helminths in human archaeological remains: a review of zoonoses in the past. Revista do Instituto de Medicina Tropical de São Paulo, São Paulo, v. 51, p. 119-130, 2009.

SWABE, J. Animals, disease and human society: human-animal relations and the rise of veterinary medicine. New York: Routledge, 1999. $196 \mathrm{p}$.

VERCRUYSSE, J.; REW, R. S. Macrocyclic lactones in antiparasitic therapy. Oxon: CAB International, 2002. $432 \mathrm{p}$.

WAGUESPACK, N. M. Colonization of the Americas: Disease ecology and the paleoindian lifestyle. Human Ecology, New York, v. 30, p. 227-243, 2002.

ZUMPT, F. Myiasis in man and animals in the Old World. London: Butterworth, 1965. $267 \mathrm{p}$. 